\section{RSP}

http://www.rsp.fsp.usp.br/

\title{
Factors associated with the contraindicated use of oral contraceptives in Brazil
}

\author{
Daniele Aparecida Silva Corrêa', Mariana Santos Felisbino-Mendes", Mayara Santos Mendes', \\ Deborah Carvalho Malta", Gustavo Velasquez-Melendez"
}

' Programa de Pós-Graduação em Enfermagem. Escola de Enfermagem. Universidade Federal de Minas Gerais. Belo Horizonte, MG, Brasil

" Departamento de Enfermagem Materno-Infantil e Saúde Pública. Escola de Enfermagem. Universidade Federal de Minas Gerais. Belo Horizonte, MG, Brasil

Correspondence:

Gustavo Velasquez-Melendez Escola de Enfermagem - UFMG

Av. Professor Alfredo Balena, 190

Santa Efigênia

30130-100 Belo Horizonte,

MG, Brasil

E-mail: guveme@ufmg.br

Received: 12 Jan 2015

Approved: 3 Dec 2015

How to cite: Corrêa DAS

Felisbino-Mendes MS, Mendes MS,

Malta DC, Velasquez-Melendez

G. Factors associated with the

contraindicated use of oral

contraceptives in Brazil. Rev Saude

Publica. 2017:51:1.

Copyright: This is an open-access article distributed under the terms of the Creative Commons Attribution License, which permits unrestricted use, distribution, and reproduction in any medium, provided that the original author and source are credited.

\section{ABSTRACT}

OBJECTIVE: To estimate the prevalence of the contraindicated use of oral contraceptives and the associated factors in Brazilian women.

METHODS: 20,454 women who answered the VIGITEL survey in 2008 also participated in this study, of which 3,985 reported using oral contraceptives. We defined the following conditions for the contraindicated use of contraceptives: hypertension; cardiovascular diseases such as heart attack, stroke/cerebrovascular accident; diabetes mellitus; being smoker and 35 years old or older. We estimated the prevalence and $95 \%$ confidence intervals of contraindicated use in users of oral contraceptives and the factors associated with contraindication by prevalence ratio and $95 \%$ confidence intervals.

RESULTS: In the total population, 21\% (95\%CI 19.7-21.9) of women showed some contraindication to the use of oral contraceptives, of which $11.7 \%$ (95\%CI 10.6-13.7) belonged to the group of users of oral contraceptives. The most frequent contraindication in users of oral contraceptives was hypertension (9.1\%). The largest proportion of women with at least one contraindication was aged between 45 and 49 years $(45.8 \%)$ and with education level between zero and eight years $(23.8 \%)$. The prevalence of contraindication to oral contraceptives was higher in women less educated (zero to eight years of study) $(\mathrm{PR}=2.46 ; 95 \% \mathrm{CI} 1.57-3.86 ; \mathrm{p}<0.05)$ and with age between 35-44 years ( $\mathrm{PR}=4.00$; 95\% CI 2.34-6.83) and 45-49 years ( $\mathrm{PR}=5.59$; 95\% CI $2.90-10.75)$.

CONCLUSIONS: Age greater than or equal to 35 and low education level were demographic and iniquity factors, respectively, in the contraindicated use of oral contraceptives.

DESCRIPTORS: Contraceptives, Oral, contraindications. Prescription Drug Misuse. Risk Factors. Women's Health. Sexual and Reproductive Health. 


\section{INTRODUCTION}

About $60 \%$ of women in reproductive age use some contraceptive method ${ }^{1}$. This prevalence reaches about $70 \%$ in Brazil, and oral contraceptive pills (OCP) and female sterilization are the most common methods $(23.0 \%)^{\text {a }}$.

The OCP, when used correctly and continuously, give the woman effective and safe control of her fertility ${ }^{11,21}$. On the other hand, an online survey conducted in eight countries showed discontinuation rate of use of the method of $81 \%$, mostly due to the adverse effects of the medicine $(57 \%)^{8}$. The same study noted forgetfulness $(65 \%)$ and intake in wrong time $(67 \%)$ as frequent problems between users of the pills in the Country.

Even before the many benefits that this method can offer, such as regularization of the menstrual cycle and prevention of some types of cancer ${ }^{12}$, the use of OCP along with some conditions such as high blood pressure can increase the risk of cerebrovascular accident (CVA), acute myocardial infarction (AMI), and other adverse outcomes in women ${ }^{5}$. Besides hypertension, the following conditions contraindicate the use of OCP: diabetes mellitus with vascular disease, smoking in women with 35 years old or older, cardiovascular diseases, thromboembolism, migraine with aura, among others. In response to this situation, the Brazilian Ministry of Health and other international agencies adopted recommendations for their use $e^{\mathrm{b}, c}$. The eligibility criteria for the use of OCP can be determined by a detailed evaluation, with clinical and family history of the woman and blood pressure measurement. In some countries, access to the method is subject to previous evaluation. In the United States, in addition to the contraindications being infrequent in women in reproductive age, the prevalence of use along with contraindication is approximately $5 \%^{5,18,21}$.

One way to acquire or start the use of OCP in Brazil is by consultation with health professional in public or private health services. Another possibility is the acquisition of the drug in drugstores without mandatory prescription.

a Perpétuo MHO, Wong LLR. Desigualdade socioeconômica na utilização de métodos anticoncepcionais no Brasil: uma análise comparativa com base na PNDS 1996 a 2006. In: Ministério da Saúde. Pesquisa Nacional de Demografia e Saúde da Criança e da Mulher - PNDS 2006: dimensões do processo reprodutivo e da saúde da criança. Brasília (DF): Ministério da Saúde; 2009. Cap. 5.

b National Center for Chronic Disease Prevention and Health Promotion USA), Division of Reproductive Health. U.S. Selected practice recommendations for contraceptive use, 2013: adapted from de World Health Organization selected practice recommendations for contraceptive use, 2 nd edition. MMWR Recomm Rep. 2013;62(RR05):1-46.

cWorld Health Organization. Medical eligibility criteria for contraceptive use. 4th ed. Geneva: WHO; 2009 [cited 2014 jul]. Available from: http://www.who. int/reproductivehealth/ publications/family_ planning/9789241563888/en/ index.html

Due to the widespread use of OCP without prescription, the ignorance of the contraindicated use is very likely. This can lead to adverse health effects. A recent study assessed the knowledge of women on the effects of OCP on their health in five Brazilian cities and showed that users know little about the contraceptive method they are using ${ }^{11}$.

There are no Brazilian population surveys to assess the extent of this problem. A few studies show concern in assessing the presence of contraindications to the use of the pill among women ${ }^{5,18,21,22}$. This is relatively expected in Brazil, since most women is not under the control of health services, acquiring the pill directly from drugstores.

Knowing the trends of use of contraceptive methods and their associated factors, as well as the characteristics of women using the method, can contribute to the planning and adaptation of public policies and to better access and use by the population.

This study aimed to estimate the prevalence of contraindicated use of OCP in Brazilian women. Our hypothesis is that there are differences in prevalence of contraindicated use of OCP according to sociodemographic variables in Brazilian women.

\section{METHODS}

This study used the rotating module of questions related to the use of contraceptive methods answered by women who participated in the system of Vigilância de Fatores de Risco e Proteção para Doenças Crônicas por Inquérito Telefônico (VIGITEL) in 2008. It is composed of probabilistic samples of the adult population living in households with at least one fixed telephone line in the current year in the capitals of the 26 Brazilian States and in the Brazilian Federal District ${ }^{13}$. 
The questionnaire included questions about feeding, physical activity, smoking, alcohol consumption, self-reported morbidity, weight, and height, health situation, and sociodemographic variables. In 2008, rotating modules were incorporated in the questionnaire: possession of health insurance, access to mental health services, and use of contraceptive methods. The following questions were included: "Currently, do you use any method to prevent pregnancy?" (yes/no); "Which method do you use more frequently?" (tubal ligation, condom, injection, pill, hormonal implant, IUD, diaphragm, vasectomy - for men only -, others).

The VIGITEL interviewed 54,353 individuals in 2008, of which 32,918 were women. Of these, 21,074 had reproductive age (15 to 49 years) and constituted the population of this study (Figure).

Exclusion criteria were: women who reported being pregnant at the time of interview $(n=457)$ or who did not know ( $\mathrm{n}=112)$; and women who have not responded any alternative of the covariates of interest, such as having access to health insurance $(n=28)$ and skin color ( $\mathrm{n}=21$ ), totaling 20,454 women. Of these, $34 \%$ reported not carrying out family planning or using any contraceptive method. Compared to those who reported using some method, $23.2 \%$ reported use of oral contraceptives (Figure).

The dependent variables were constructed using the definition of contraindication to the use of oral contraceptives published in 2010 by the World Health Organization (WHO) and adopted by the Brazilian Ministry of Health (MS) ${ }^{c}$, as well as the more recent recommendation of the Centers for Disease Control in the United States ${ }^{b}$. We considered the following conditions for the contraindicated use of contraceptives: hypertension (SH) (yes/no); cardiovascular diseases (CVD) such as heart attack and stroke/CVA (cerebrovascular accident) (yes/no); diabetes mellitus (yes/no); being smoker and over 35 years old at the same time (yes/no). The occurrence of at least one of these conditions was considered a contraindication to the use of OCP.

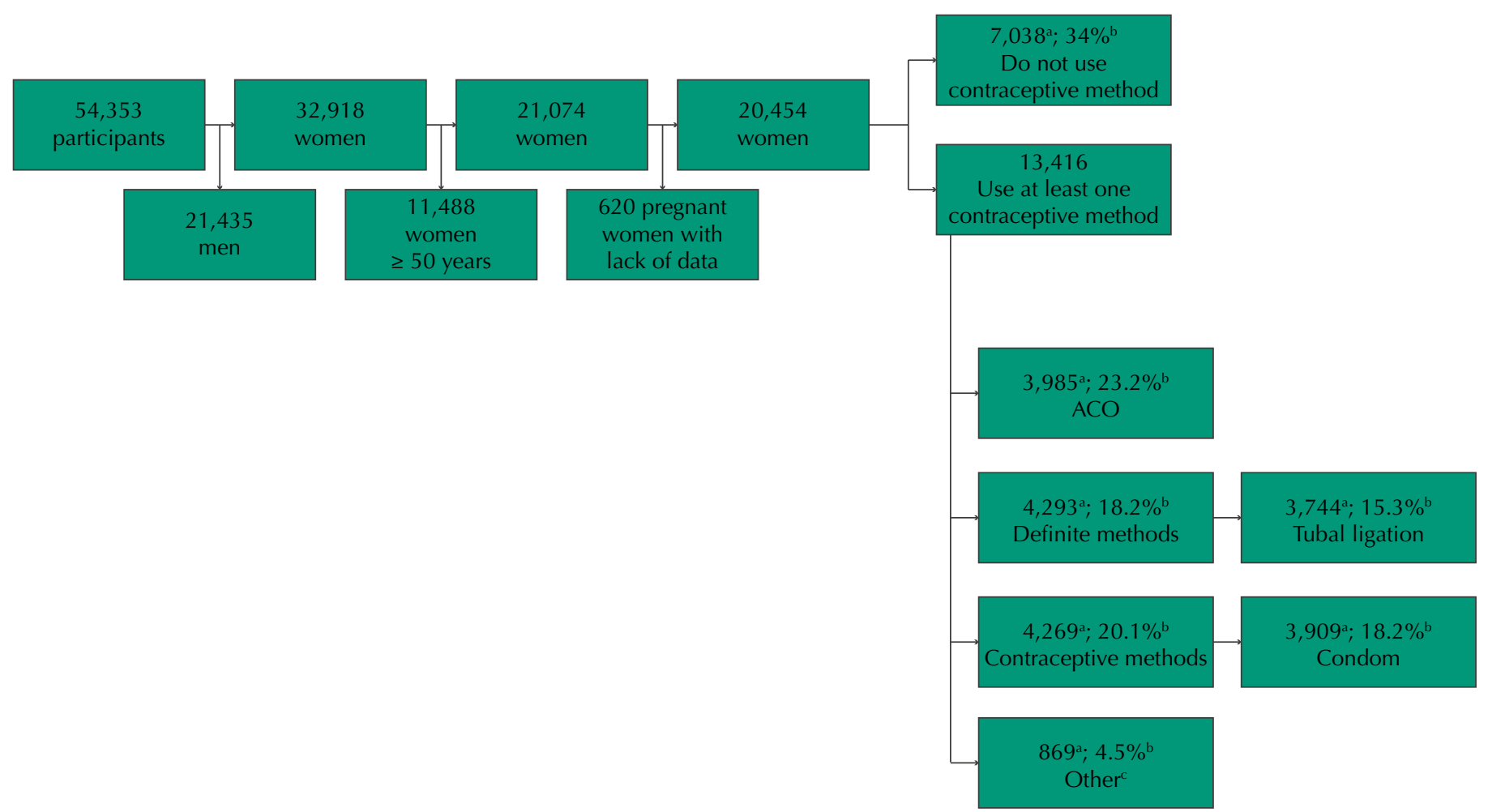

OCP: oral contraceptive pills

a sample n.

${ }^{\mathrm{b}}$ population estimate.

c intrauterine device and diaphragm.

Figure. Flowchart of the population available for study. VIGITEL, Brazil, 2008. 
The independent variables used were: age (18 to 24,25 to 34,35 to 44,45 to 49 years), education level (zero to eight, nine to 11, 12 or more years of study), skin color (white, black, brown, and others), marital status (single, married or in stable union, widow, divorced), health plan or insurance (yes/no), housing region (North, Northeast, South, Southeast, and Midwest), all self-reported.

We conducted a non-conditional analysis based on the definition of subpopulation of interest $^{19}$. Missing data and subgroups that met exclusion criteria were included in the category 0 of the variable indicating subpopulation, and the studied population was included in category 1 . This method is more suitable to estimate the variance for representative samples of large populations. We estimated the prevalence and 95\% confidence intervals (95\%CI) of the contraindications for all population and according to the use of contraceptives. For women who reported using OCP, we estimated the proportions and non adjusted prevalence ratios (PR) and 95\%CI of the use of OCP along with at least one contraindication, according to sociodemographic characteristics, using Poisson regression. Statistical differences between the proportions were evaluated by Pearson's Chi-squared test. We estimated the adjusted PR and 95\%CI. We used Wald's Chi-squared test to assess the statistical significance of the contribution of each variable in the multivariate model. A significance level of $p<0.05$ was used to reject the null hypothesis in all tests.

We used the statistical program Stata, version 12.0, and the commands of the survey module, considering the weights and representativeness of the sample.

The VIGITEL was approved by the National Research Ethics Committee for Human Beings of the Ministry of Health under Opinion 749/2006, according to the principles of the Declaration of Helsinki. As the data were obtained by telephone interview, the informed consent form was replaced by verbal consent, obtained during the telephone contacts with respondents. The researchers did not have access to the identity of participants.

\section{RESULTS}

Of 20,454 women, about $21.0 \%$ showed at least one potential contraindication to use OCP, with $11.7 \%$ of them in the group of users and $23.5 \%$ in the group of non-users (Table 1).

Among OCP users, $10.5 \%$ presented one contraindication and $1.2 \%$, two contraindication conditions (Table 1). The most frequent contraindication was systemic hypertension (SH) (15.1\%). The habit of smoking in women aged 35 years or older was the second most frequent contraindication $(2.6 \%)$ (Table 1$)$.

Table 1. Prevalence of contraindications to oral contraceptive use among Brazilian women. VIGITEL, Brazil, 2008.

\begin{tabular}{|c|c|c|c|c|c|c|c|c|c|}
\hline \multirow{3}{*}{ Contraindications } & \multirow{2}{*}{\multicolumn{3}{|c|}{$\begin{array}{l}\text { Total women } \\
(\mathrm{n}=\mathbf{2 0 . 4 5 4})\end{array}$}} & \multicolumn{6}{|c|}{ Use of OCP } \\
\hline & & & & \multicolumn{3}{|c|}{$\begin{array}{c}\text { Yes } \\
(\mathbf{n}=3.985) \\
\end{array}$} & \multicolumn{3}{|c|}{$\begin{array}{c}\text { No } \\
(\mathrm{n}=16.469)\end{array}$} \\
\hline & $\mathbf{n}$ & $\%$ & $95 \% \mathrm{Cl}$ & $\mathbf{n}$ & $\%$ & $95 \% \mathrm{Cl}$ & $\mathbf{n}$ & $\%$ & $95 \% \mathrm{Cl}$ \\
\hline At least one contraindication & 4,040 & 20.8 & $19.7-21.9$ & 480 & 11.7 & $10.6-13.7$ & 3,560 & 23.5 & $22.3-24.8$ \\
\hline \multicolumn{10}{|l|}{ Number of contraindications } \\
\hline 1 & 3,454 & 17.4 & $16.4-18.4$ & 426 & 10.5 & $8.9-12.4$ & 3,028 & 19.5 & $18.4-20.7$ \\
\hline 2 & 531 & 3.1 & $2.6-3.7$ & 50 & 1.2 & $0.8-1.9$ & 481 & 3.6 & $3.0-4.3$ \\
\hline 3 or + & 55 & 0.3 & $0.1-0.5$ & 4 & 0.03 & $0.01-0.1$ & 51 & 0.4 & $0.2-0.6$ \\
\hline \multicolumn{10}{|l|}{ Types of contraindications } \\
\hline $\mathrm{SH}$ & 2,874 & 15.1 & $14.1-16.1$ & 354 & 9.1 & $7.6-10.8$ & 2,520 & 16.9 & $15.7-18.1$ \\
\hline Smokers and $\geq 35$ years & 1,156 & 6.1 & $5.5-6.7$ & 112 & 2.6 & $1.8-3.7$ & 1,044 & 7.1 & $6.4-8.0$ \\
\hline DM & 451 & 2.2 & $1.8-2.6$ & 51 & 0.9 & $0.6-1.4$ & 400 & 2.6 & $2.2-3.1$ \\
\hline CVD & 201 & 1.1 & $0.8-1.5$ & 21 & 0.5 & $0.3-0.9$ & 180 & 1.3 & $0.9-1.8$ \\
\hline
\end{tabular}

OCP: oral contraceptive pills; SH: systemic hypertension; DM: diabetes mellitus; CVD: cardiovascular disease 
There was higher prevalence of contraindicated use in women who have low education level (zero to eight years of study), when compared with those with more education ( $\mathrm{PR}=3.76$; 95\%CI 2.44-5.80) (Table 2). This prevalence was also high in women aged 45-49 years when compared with younger ones $(\mathrm{PR}=7.30$; $95 \% \mathrm{CI} 4.2-12.8)$. The contraindicated use of OCP was more frequent in separated/divorced women (27.3\%), followed by widow women (15\%). A higher proportion of women presented at least one contraindication among those who had health plan or insurance $(14.8 \%)(\mathrm{p}<0.05)$. The contraindication was more prevalent in women classified as other (yellow, red/indigenous, do not know, and would not inform) (21\%), followed by brown (13.6\%) and black women (11.2\%). The North region concentrated most women with at least one contraindication (14\%), followed by South (11.9\%) and Southeast (11.8\%).

The factors that remained associated with contraindications in women using OCP were low education level and age $\geq 35$ years in the adjusted analysis (Table 3).

Table 2. Prevalence and 95\% confidence intervals of contraindicated use of oral contraceptive among users of the method, according to sociodemographic characteristics. VIGITEL, Brazil, 2008.

\begin{tabular}{|c|c|c|c|c|c|c|c|}
\hline \multirow{2}{*}{ Sociodemographic characteristics } & \multicolumn{7}{|c|}{ Women using OCP } \\
\hline & $\mathbf{n}$ & $\%$ & $95 \% \mathrm{Cl}$ & $\mathbf{p}^{\mathbf{a}}$ & PR & $95 \% \mathrm{Cl}$ & $\mathbf{p}^{\mathbf{b}}$ \\
\hline Education level (years) & & & & $<0.0001$ & & & \\
\hline 12 and more & 1,840 & 6.3 & $4.4-9.0$ & & 1.0 & - & - \\
\hline 9 to 11 & 1,670 & 10.4 & $8.2-13.0$ & & 1.6 & $1.1-2.5$ & 0.022 \\
\hline 0 to 8 & 475 & 23.8 & $18.5-30.0$ & & 3.8 & $2.4-5.8$ & $<0.000$ \\
\hline Age (years) & & & & $<0.0001$ & & & \\
\hline 18 to 24 & 1,172 & 6.2 & $3.4-9.6$ & & 1.0 & - & - \\
\hline 25 to 34 & 1,858 & 7.5 & $5.7-9.7$ & & 1.2 & $0.7-2.0$ & 0.493 \\
\hline 35 to 44 & 823 & 30.7 & $25.0-37.0$ & & 4.9 & $3.0-8.0$ & $<0.000$ \\
\hline 45 to 49 & 132 & 45.8 & $31.3-61.1$ & & 7.3 & $4.2-12.8$ & $<0.000$ \\
\hline Marital status & & & & 0.0001 & & & \\
\hline Single & 2,021 & 8.8 & $6.8-11.3$ & & 1.0 & - & - \\
\hline Married & 1,802 & 14.8 & $12.1-18.1$ & & 1.7 & $1.2-2.3$ & 0.001 \\
\hline Widow & 26 & 15.0 & $5.3-35.8$ & & 1.7 & $0.6-4.7$ & 0.303 \\
\hline Separated/Divorced & 136 & 27.3 & $15.7-43.1$ & & 3.1 & $1.8-5.5$ & $<0.000$ \\
\hline Has health plan or insurance & & & & 0.003 & & & \\
\hline Yes & 2,308 & 14.8 & $12.2-17.7$ & & 1.0 & - & - \\
\hline No & 1,677 & 9.2 & $7.1-11.9$ & & 0.6 & $0.4-0.8$ & 0.004 \\
\hline Skin color & & & & 0.176 & & & \\
\hline White & 1,832 & 9.9 & $7.7-12.5$ & & 1.0 & - & - \\
\hline Black & 190 & 11.2 & $6.6-18.5$ & & 1.1 & $0.6-2.0$ & 0.660 \\
\hline Brown & 1,942 & 13.6 & $11.0-16.8$ & & 1.4 & $1.0-1.9$ & 0.530 \\
\hline Other & 21 & 21.0 & $5.0-57.2$ & & 2.1 & $0.6-7.8$ & 0.255 \\
\hline Region & & & & 0.844 & & & \\
\hline North & 928 & 14.0 & 10.3-18.9 & & 1.0 & - & - \\
\hline Northeast & 979 & 11.5 & $8.8-15.0$ & & 0.8 & $0.5-1.3$ & 0.334 \\
\hline Midwest & 722 & 10.7 & $8.3-13.7$ & & 0.8 & $0.5-1.1$ & 0.179 \\
\hline Southeast & 734 & 11.8 & $9.0-15.3$ & & 0.8 & $0.6-1.2$ & 0.394 \\
\hline South & 632 & 11.9 & $9.2-15.2$ & & 0.8 & $0.6-1.2$ & 0.409 \\
\hline
\end{tabular}

OCP: oral contraceptive pills; PR: prevalence ratio

a Pearson's Chi-squared.

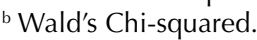


Table 3. Prevalence ratios and 95\% confidence intervals for the presence of at least one contraindication among users of oral contraceptive, according to sociodemographic characteristics. VIGITEL, Brazil, 2008.

\begin{tabular}{|c|c|c|c|}
\hline \multirow{2}{*}{ Sociodemographic characteristics } & \multicolumn{3}{|c|}{ Contraindication } \\
\hline & Adjusted PR & $95 \% \mathrm{Cl}$ & p* \\
\hline \multicolumn{4}{|l|}{ Education level (years) } \\
\hline 12 and more & 1.0 & - & - \\
\hline 9 to 11 & 1.7 & $1.1-2.5$ & 0.014 \\
\hline 0 to 8 & 2.5 & 1.6-3.9 & $<0.000$ \\
\hline \multicolumn{4}{|l|}{ Age (years) } \\
\hline 18 to 24 & 1.0 & - & - \\
\hline 25 to 34 & 1.1 & $0.6-1.9$ & 0.727 \\
\hline 35 to 44 & 4.0 & $2.3-6.8$ & $<0.000$ \\
\hline 45 to 49 & 5.6 & $2.9-10.7$ & $<0.000$ \\
\hline \multicolumn{4}{|l|}{ Marital status } \\
\hline Single & 1.0 & - & - \\
\hline Married & 1.0 & $0.7-1.4$ & 0.939 \\
\hline Widow & 0.6 & $0.2-1.8$ & 0.354 \\
\hline Separated/Divorced & 1.5 & $0.8-2.8$ & 0.160 \\
\hline \multicolumn{4}{|l|}{ Has health plan or insurance } \\
\hline Yes & 1.0 & - & - \\
\hline No & 0.9 & $0.7-1.2$ & 0.522 \\
\hline \multicolumn{4}{|l|}{ Skin color } \\
\hline White & 1.0 & - & - \\
\hline Black & 0.9 & $0.5-1.7$ & 0.754 \\
\hline Brown & 1.1 & $0.8-1.6$ & 0.450 \\
\hline Other & 2.4 & $0.7-8.6$ & 0.162 \\
\hline \multicolumn{4}{|l|}{ Region } \\
\hline North & 1.0 & - & - \\
\hline Northeast & 0.8 & $0.5-1.2$ & 0.522 \\
\hline Midwest & 0.8 & $0.6-1.2$ & 0.316 \\
\hline Southeast & 0.8 & $0.6-1.3$ & 0.444 \\
\hline South & 0.8 & $0.6-1.2$ & 0.353 \\
\hline
\end{tabular}

PR: Prevalence Ratio

* Wald's Chi-squared.

\section{DISCUSSION}

About 20\% of Brazilian women showed some condition that contraindicates the use of OCP. This proportion was $11.7 \%$ in women using OCP. The main condition for contraindicated use was $\mathrm{SH}$, followed by age over 35 years along with smoking.

Most studies that measured the magnitude of use of OCP in the presence of contraindication were carried out with North American populations ${ }^{5,18,21,22}$. Data from the National Health and Nutrition Examination Survey (NHANES) showed contraindication prevalence of $6 \%$ among users of OCP in the United States, half of what we found, and 19\% among non-users of the method $^{18}$. Another study showed higher prevalence of contraindication among American women who buy OCP on drugstores (13\%) when compared to those served in clinics (9\%). However, an internet survey showed that $23.7 \%$ of North American users of OCP had some contraindication condition ${ }^{22}$. On the other hand, the North American Project CHOICE showed that $3 \%$ of women used OCP with some contraindication, showing great variability in the estimation of this parameter, which could be explained by the different samples and contexts of the women accessed in each study. 
There are no similar population studies using a representative sample population in Brazil. A local study, conducted in Pelotas (RS), between 1992 and 1999, showed that, among the 279 users of OCP, $22.2 \%$ presented some contraindication for their consumption. The most prevalent condition was smoking in women over 35 years, followed by $\mathrm{SH}^{3}$.

In this study, the prevalence of contraindications to use OCP was similar to that of the presented studies. Thus, even if the use of OCP is safe as a measure of fertility control, their use along with a contraindication is an indicator of problems in the quality of actions for family planning and integrality of health actions. The sharp growth in the use of contraceptive methods in Brazil in recent decades reached about $80 \%$ of women in reproductive age in $2006^{\mathrm{a}}$. Among the methods, the use of OCP is expected to keep growing, since they are the second most widely used contraceptive method in Brazil, followed by tubal ligature, often associated with the epidemic of Caesarean sections in force since the 90s. One must expect a behavior similar to the world trend, in which the OCP method may be the first election. Thus, the promotion of proper use is essential, that is, that the method is used by women who meet the eligibility criteria. The use along with a contraindication may result in damages to health, putting it at risk of more serious events.

Self-reported SH was the most prevalent contraindication, confirming studies carried out with other populations ${ }^{5,21}$. Women whose blood pressure was not measured before starting the use of OCP showed increased risk of acute myocardial infarction (AMI). Therefore, their blood pressure must be measure before starting the use of the method ${ }^{20, c}$. The prolonged use of OCP may increase twice the chance of developing hypertension ${ }^{15}$. This indicates that hypertension can be aggravated with the use of OCP, tripling the odds ratio $(\mathrm{OR}=2.67)$ of non-control of blood pressure ( $\geq 140 / 90 \mathrm{mmHg}$ ) when compared to non-users ${ }^{10}$. On the other hand, the suspension of OCP in hypertensive women reduced in $15 \mathrm{mmHg}$ the systolic blood pressure and in $10 \mathrm{mmHg}$ the diastolic blood pressure ${ }^{10}$. In this study, we observed higher proportion of contraindicated use among women over 35 years, known to be more vulnerable to the occurrence of hypertension and other diseases, more prevalent with age.

The second most prevalent contraindication was smoking and age $\geq 35$ years together. The risk of AMI in women who smoke and have less than 35 years is 10 times greater than that of those who do not smoke ${ }^{20}$, and this risk in women older than 35 is higher regardless of smoking. Thus, the risk of AMI among these users also increases with the coexistence of cardiovascular risk factors, such as smoking, which potentiates this effect on women over $35^{2,20}$. The number of cigarettes also affects this evaluation, but this information is not available on VIGITEL, 2008.

The contraindicated use of OCP is also a cardiovascular risk factor, especially in women over 30 years old. This is troubling, since the main cause of morbidity and mortality in Brazil are the cardiovascular system diseases ${ }^{\mathrm{d}}$. Facing this problem means preventing risk factors, including the contraindicated use of $\mathrm{OCP}^{3}$.

${ }^{\mathrm{d}}$ Institute for Health Metrics and Evaluation (IHME). Global Burden of Disease (GBD) profile: Brazil. Seattle: IHME; 2013 [cited 2013 Apr 30). Available from: http://www. healthmetricsandevaluation.org/ $\mathrm{gbd} /$ country-profiles

e Cabral CS. Socialização contraceptiva e o aprendizado da sexualidade: uma abordagem socioantropológica do processo de construção da prática contraceptiva. In: Anais do $18^{\circ}$ Encontro Nacional de Estudos Populacionais; 13 a 23 de Novembro, 2012; Águas de Lindóia/SP-Brasil. Associação Brasileira de Estudos Populacionais; 2012.

This study showed that women over 34 years, separated/divorced, with private health plan, and low education level presented higher prevalence of contraindication to the use of OCP. Explanations of these findings as a whole are relatively complex, since they involve factors of diverse and sometimes speculative nature, such as access to information and effective management of contraception, which involves issues such as the criterion of effectiveness, unimpeded sexuality, and female protagonism that the use of the pill represents to many women ${ }^{e}$. In addition, there is reproductive assistance concentrated in women who experience the pregnancy-puerperal cycle ${ }^{7}$, leaving women with extremes of age, as adolescents and older women, on the sidelines of the reproductive planning. Self-medication may still be a result of individual social and political processes, not necessarily of access to method and information ${ }^{4}$. It can also result from feminine socialization marked by learning with friends, from the acquisition of the medicine in drugstores, and from the dependence of this for contraception ${ }^{\text {e }}$. Finally, the pill was reported as an easier method to use and obtain in health services $^{\mathrm{e}}$. However, a regional study showed that neither the indication for use of OCP in 
health services nor getting the medicine on the service itself have improved its fitness when compared with the acquisition by the user herself 6 . We were not able to show this result here due to the lack of data about the source of recommendation of its use.

Education level was an iniquity factor to the use of OCP: there was higher prevalence of contraindication in women with low educational level. The education level is expected to improve the proper choice of OCP. Better educated women used contraceptive methods more often. Those with less education had more children than they wanted to, and the most prevalent method was tubal ligation ${ }^{\mathrm{d}}$. As is the case in Brazil, in high-income countries, the difficulty of choice of appropriate method can be extended to women who did not finish higher education ${ }^{22}$. Women with more education may have greater understanding of information about the method they wish to use and the risks inherent in it.

The unequal access to contraception can also be related to increased access to the diversity of methods by women with more education. The findings point to the difficulty of SUS in achieving greater democratization of access to the wide variety of contraceptive methods, as well as to the inefficiency in the supply of reproductive planning assistance in primary health-care.

One of the main limitations of this study is the use of telephone interviews. The coverage of fixed telephone lines ranges from $34 \%$ to $82 \%$ in the capitals in which the samples were drawn. However, the system presents response rates above $60 \%$. Because of its convenience and relatively low cost, the use of health surveillance systems by telephone survey is an efficient and practical methodology to the context of health surveillance. A comparative study between researches conducted by face-to-face interviews and telephone survey provides evidence in favor of the latter, provided that it is performed with well-structured questionnaires and trained interviewers ${ }^{14,17}$. This limitation can be circumvented with the inclusion of poststratification weights of the samples. The use of post-stratification corrections obtained by the weights estimated using statistical strategies effectively reduces the risk of systematic errors related to fixed telephony coverage.

Another limitation of this study is the self-reported data, since subclinical events may be underestimated. This can be due to ignorance of the health conditions of the individual, as a result of many reasons, such as lack of access to health services, lack of consensus among doctors about the criteria used to report these conditions to the bearer, individual limitations regarding the capacity of understanding of individuals about their own health condition.

Some important contraindications to the use of $\mathrm{OCP}$, such as thromboembolism and migraine with aura, were not measured by VIGITEL, 2008. For this reason, the prevalence of use of OCP along with contraindication may be underestimated. Data concerning other aspects of the reproductive history of women were also not available in this survey. These variables can potentially be determinants of the use of contraceptive methods, indicating that the final analysis can incorporate residual confusion.

The non-characterization of the type of OCP reported by the user in terms of their hormonal composition can be considered another potential limitation. OCP composed only of progestogens have contraindications only for more serious diseases. However, the use of this type of contraceptive is relatively low, probably because of the side effects, such as breakthrough bleeding, present in about $70 \%$ of women using this method ${ }^{9,16}$. Thus, the results of estimates of contraindicated use should be faced with caution and regarded as epidemiological marker events of their use.

The results of this study estimated a prevalence of almost $12 \%$ of use of OCP along with contraindications among Brazilian women in reproductive age. Education level was an inequity factor in the contraindicated use of OCP, and the group of women over 35 years presented itself as a potential surveillance group in their contraindicated use. This study may help identifying the possible existence of an undesirable iniquity in the reproductive health-care of Brazilian women. 
The findings of this study point to the need for reviewing the activities and services concerning the reproductive planning in the Country, including counseling and free informed choice. Even with the availability of OCP in drugstores counters, one must empower women about their risks and benefits, as well as of other options for birth control. The identification of inequalities in the access and use of health services is focus of attention of academic researches and public administrators, for it provides important information to the planning of public health actions. Surveillance systems can help monitoring possible trends of the outcome studied.

\section{REFERENCES}

1. Alkema L, Kantorova V, Menozzi C, Biddlecom A. National, regional, and global rates and trends in contraceptive prevalence and unmet need for family planning between 1990 and 2015: a systematic and comprehensive analysis. Lancet. 2013;381:1642-52.

2. Brito MB, Nobre F, Vieira CS. Contracepção hormonal e sistema cardiovascular. Arq Bras Cardiol. 2011;96(4):81-9.

3. Dias-da-Costa JS, Gigante DP, Menezes AMB, Olinto MTA, Macedo S, Britto MAP et al. Uso de métodos anticoncepcionais e adequação de contraceptivos hormonais orais na cidade de Pelotas, Rio Grande do Sul, Brasil: 1992 e 1999. Cad Saude Publica. 2002;18(1):93-9. DOI:10.1590/S0102-311X2002000100010

4. Fainzang S. The other side of medicalization: self-medicalization and self-medication. Cult Med Psychiatry. 2013;37(3):488-504. DOI:10.1007/s11013-013-9330-2

5. Grossman D, White K, Hopkins K, Amastae J, Shedlin M, Potter JE. Contraindications to combined oral contraceptives among over-the-counter compared with prescription users. Obstet Gynecol. 2011;117(3):558-65. DOI:10.1097/AOG.0b013e31820b0244

6. Hardy EE, Moraes TM, Faúndes A, Vera S, Pinotti JA. Adequação do uso de pílula anticoncepcional entre mulheres unidas. Rev Saude Publica. 1991;25(2):96-102. DOI:10.1590/S0034-89101991000200003

7. Heilborn ML, Portella AP, Brandão ER, Cabral CS; Grupo CONPRuSUS. Assistência em contracepção e planejamento reprodutivo na perspectiva de usuárias de três unidades do Sistema Único de Saúde no Estado do Rio de Janeiro, Brasil. Cad Saude Publica. 2009;25(Suppl 2):s269-78. DOI:10.1590/S0102-311X2009001400009

8. Hooper DJ. Attitudes, awareness, compliance and preferences among hormonal contraception users: a global, cross-sectional, self-administered, online survey. Clin Drug Investig. 2010;30(11):749-63. DOI:10.2165/11538900-000000000-00000

9. Kovacs G. Progestogen-only pills and bleeding disturbances. Human Reprod. 1996;11 Suppl 2:20-3.

10. Lubianca JN, Faccin CS, Fuchs FD. Oral contraceptives: a risk factor for uncontrolled blood pressure among hypertensive women. Contraceptions. 2003;67(1):19-24. DOI:10.1016/S0010-7824(02)00429-8

11. Machado BR, Melo NR, Prota FE, Lopes GP, Megale A. Women's knowledge of health effects of oral contraceptives in five Brazilian cities. Elsevier. 2012;86(6):698-703. DOI:10.1016/j.contraception.2012.05.016

12. Maguire K, Westhoff $\mathrm{C}$. The state of hormonal contraception today: established and emerging noncontraceptive health benefits. Am J Obstet Gynecol. 2011;205(4 Suppl:S4-8. DOI:10.1016/j.ajog.2011.06.056

13. Malta DC, Bernal RTI, Oliveira M. Tendências dos fatores de risco de doenças crônicas não transmissíveis, segundo a posse de planos de saúde, Brasil, 2008 a 2013. Cienc Saude Coletiva. 2015;20(4):1005-16. DOI:10.1590/1413-81232015204.14712014

14. Moura EC, Malta D, Morais Neto OLD, Moteiro CA. Prevalence and social distribution of risk factors for chronic noncommunicable diseases in Brazil. Rev Panam Salud Publica. 2009;26(1). DOI:10.1590/S1020-49892009000700003

15. Park H, Kim K. Associations between oral contraceptive use and risks of hypertension and prehypertension in a cross-sectional study of Korean women. BMC Womens Health. 2013;13:39. DOI:10.1186/1472-6874-13-39 
16. Porter C, Rees COM. Bleeding problems and progestogen-only contraception. J Fam Plann Reprod Health Care. 2002;28(4):178-81. DOI:10.1783/147118902101196784

17. Segri NJ, Cesar CLG, Barros MBA, Alves MCGP, Carandina L, Goldbaum M. Inquérito de saúde: comparação dos entrevistados segundo posse de linha telefônica residencial. Rev Saude Publica. 2010;44(3):503-12. DOI:10.1590/S0034-89102010005000012

18. Shortridge E, Miller K. Contra-indications to oral contraceptive use among women in the United States 1999-2001. Contraception. 2007;75(5):355-60. DOI:10.1016/j.contraception.2006.12.022

19. West BT, Berglund P, Heeringa SG. A closer examination of subpopulation analysis of complex sample survey data. Stata J. 2008;8(4):520-31.

20. World Health Organization. 1997 Guidelines for the management of mild hypertension: memorandum from a WHO/ISH meeting. Bull World Health Organization. 1997;71(5):503-17.

21. Xu H, Eisenberg DL, Madden T, Secura GM, Peipert JF. Medical contraindications in women seeking combined hormonal contraception. Am J Obstet Gynecol. 2014;210(3):210.e1-5. DOI:10.1016/j.ajog.2013.11.023

22. $\mathrm{Yu} \mathrm{J}, \mathrm{Hu} \mathrm{XH}$. Inappropriate use of combined hormonal contraceptives for birth control among women of reproductive age in the United States. J Womens Health (Larchmt). 2013;22(7):595-603. DOI:10.1089/jwh.2012.3955

Funding: Brazilian Ministry of Health, Agreement 188 of 2012 (Process FNS 25000.201638/2012-39).

Authors' Contribution: Conception and planning of the study: DASC, GVM, MSFM, MSM. Data analysis and interpretation: MSFM, MSM, GVM. Preparation and writing of the manuscript: DASC, MSFM, MSM, DCM, GVM. Critical review of the manuscript: MSFM, DCM, GVM. Final approval: DASC, MSFM, MSM, DCM, GVM.

Acknowledgments: Part of the results of this manuscript were presented at the 20th World Congress of Epidemiology in Anchorage, Alaska, in 2014, with the support of the International Epidemiological Association by a prize this study won, titled "the International Epidemiological Association (IEA) Early Career Epidemiologists (ECE) best abstract competition.”

Conflict of Interest: The authors declare no conflict of interest. 